\title{
The Study on Patient Dissatisfaction with Medical Services to define an Indicator of the Healthcare Management in the Ton and Issyk-Kul Regional Hospitals of Kyrgyzstan
}

\author{
Bolotbek Shayahmetov ${ }^{1}$, Yoshitoku Yoshida ${ }^{2 *}$, Ernis Bokchubaev ${ }^{3}$, Eiko Yamamoto $^{4}$ and Joshua A. Reyer ${ }^{5}$ \\ ${ }^{1}$ Department of Healthcare Management and Economics, Kyrgyz State Medical Institute of Continuous Education, Kyrgyzstan \\ ${ }^{2}$ Faculty of Nursing, Shubun University, 6 Nikko-cho, Ichinomiya, 491-0938, Japan \\ ${ }^{3}$ Department of Healthcare Management and Economics, Kyrgyz State Medical Institute of Continuous Education, Kyrgyzstan \\ ${ }^{4}$ Department of Healthcare Administration, Nagoya University Graduate School of Medicine, Nagoya, Japan, 65 Tsurumaicho, Showa-ku, Nagoya 466-8550, Japan \\ ${ }^{5}$ Department of Healthcare Administration, Nagoya University Graduate School of Medicine, Nagoya, Japan, 65 Tsurumaicho, Showa-ku, Nagoya 466-8550, Japan
}

\begin{abstract}
Objectives: This study aimed to define major criteria potentially influencing patient dissatisfaction, using data from two regional hospitals (RH) to identify priority areas for potential care improvement.

Method: This was a cross-sectional study conducted from July to September 2014. Participants were 500 patients (230 at Ton RH and 270 at Issyk-Kul RH) selected during the designated period. Participants were surveyed with dissatisfaction measures, including 21 perceived quality-of-care indicators, divided into organizational, competency and informational aspects. We estimated associations between patient dissatisfaction and these aspects in designated hospitals using Chi-square tests. The organizational aspect included 11 criteria.

Results: The long waiting period for hospitalization and untimely physicians' rounds in Ton RH (79.1\% in both characteristics) caused dissatisfaction. At Issyk-Kul $\mathrm{RH}, 78.5 \%$ of patients were dissatisfied with securing of nutrition and food quality. There was a significant difference in the criterion of timely observation by doctors between the two RH ( $\mathrm{p}=0.006)$. Of the nine parameters of competency, significant differences were obtained at both RHs for insufficiently friendly nurse attitudes toward patients $(\mathrm{p}<0.001)$, and completeness of primary medical check ( $\mathrm{p}=0.004)$. Regarding the information aspect, $68.7 \%$ of patients in Ton RH and $69.3 \%$-in Issyk-Kul RH were dissatisfied with informational materials availability.
\end{abstract}

Conclusions: Our findings suggest that clinical staff should be implemented to learn patients' expectations and opinions about hospital services. Securing high patient satisfaction is equally important for a hospital management team.

\section{Introduction}

Kyrgyzstan is a landlocked country in Central Asia with a total territory of 199,900 square kilometers. It is extremely mountainous, with almost $90 \%$ of its territory 1,500 meters or more above sea level. It has a low average population density of 26 people per square kilometer, with high population concentrations in river valleys and along lakesides. In 2014, it had a population of 5.4 million, $64 \%$ of whom were living in rural areas. The death rate was 6.74 deaths per 1,000 people in 2014 . The population is young; giving that $29 \%$ are aged 14 years or younger. Kyrgyzstan has undertaken wide-ranging health system reforms in a challenging socioeconomic and political context [1]. The country developed two major health reform programs after becoming independent: Manas (1996-2006) and Manas Taalimi (2006-2010). These reforms introduced comprehensive structural changes to the healthcare delivery system in order to strengthen primary healthcare, develop family medicine, and restructure the hospital sector. The third reform was called Den-Sooluk (2012-2016). The major objectives of this reform have included quality improvements in the priority programs for mother and child health, cardiovascular diseases, tuberculosis, and HIV/AIDS; strengthening public health, and medical education.

The healthcare system must necessarily correspond to patients' needs and requirements. Sociological research of patient feedback on healthcare quality plays an important role in obtaining valuable operational information for facility management. Medical and sociological monitoring based on the results of participant surveys permits exposure of significant problems that affect medical service quality and allow active and prompt situation management [2]. Patient satisfaction is considered one desired healthcare outcome and is directly related to health services utilization. Asking patients what they think about the care and treatment they received is an important step toward improving care quality and ensuring that local health services meet patients' needs. Patient satisfaction is of fundamental importance to measure care quality because it provides information on the providers' success in meeting patient values and expectations [3].

In 1985, Swan suggested that patients' positive opinions about services received are a matching process between a set of generally

Correspondence to: Yoshitoku Yoshida, Faculty of Nursing, Shubun University, 6 Nikko-cho, Ichinomiya, 491-0938, Japan. Tel: +81-586-45-2101 (Ext: 10502); Fax: +81586454410; E-mail: yoshida.yo@shubun.ac.jp

Key words: evaluation, dissatisfaction, healthcare, Kyrgyzstan, patient satisfaction Received: August 28, 2016; Accepted: October 27, 2016; Published: October 31, 2016 
Shayahmetov B (2016) The Study on Patient Dissatisfaction with Medical Services to define an Indicator of the Healthcare Management in the Ton and Issyk-Kul Regional Hospitals of Kyrgyzstan

accepted quality expectations and their personal past involvement. Many articles about patient satisfaction suggested the following significant relationship: satisfaction is the result of perceiving service implementation against expectations. Willingness to buy, or to return to receive the same services is the effect of satisfaction. Expectations and willingness for services create alternatives for patients. The more pleased the patients are, the greater the satisfaction levels will be [4].

Efficacy, effectiveness, efficiency, optimality, acceptability, legitimacy, and equity are seven main factors suggested by Donabedian [5]. Significant changes in healthcare service evaluation and enhancement are opening new healthcare portraits for the service user. Assessment of patient satisfaction allows hospital managers to investigate the extent to which their service meets the needs of patient groups [6].

The aims of this study were to define major criteria that may influence patient dissatisfaction, based on comparing patient questionnaires at Ton Regional Hospital (RH) and Issyk-Kul RH of Kyrgyzstan, and to then formulate proposals to improve healthcare management using different evaluation methods. We focused on Ton $\mathrm{RH}$, located in a remote village far from the capital, with poor social and medical infrastructure. For contrast, we chose Issyk-Kul RH, with more efficient management, sufficient medical staff, better medical equipment, and the higher incomes of those working in a recreational area. The hospitals had similar numbers of beds and structures, but Issyk-Kul RH medically treated 900-plus more patients annually than Ton RH.

\section{Materials and methods}

This was a cross-sectional study designed to examine patient dissatisfaction in two selected secondary hospitals in Kyrgyzstan: Ton $\mathrm{RH}$ and Issyk-Kul RH. Participants were 230 selected patients in Ton $\mathrm{RH}$ and 270 patients in Issyk-Kul RH. Inclusion criteria were patients over 18 years old who were admitted for 7 to 10 days. Data collection took place from July to September 2014. The questionnaire was developed by the authors based on the standardized patient satisfaction questionnaire. The initial part of the questionnaire consisted of five socio-demographic characteristics such as age, gender, social status, education, and marital status. The main part of this questionnaire comprised 21 questions regarding hospital activity. Multiple-choice questions were included to evaluate satisfaction factors. Patients rated each item on a five-point scale: 1-completely dissatisfied, 2-somewhat dissatisfied, 3-neutral (average), 4-somewhat satisfied, 5-completely satisfied. To evaluate the patient's dissatisfaction with organizational aspects in Ton and Issyk-Kul Regional Hospitals of Kyrgyzstan, we categorized answers of 1 to 3 points as "dissatisfied."

Data were analyzed with the chi-square test using the Statistical Package for Social Sciences (SPSS) version 22.0 and corrected after examining inclusion criteria, completeness and summary measures. All of the statistical tests were two-tailed and p-values $<0.05$ were considered statistically significant.

This study was approved by the Ethical Committee of Kyrgyz State Medical Institute of Advanced Qualification, Ministry of Health, Kyrgyzstan in September 2014.

\section{Results}

Table 1 shows the characteristics and indicators of Ton RH and Issyk-Kul RH of Kyrgyzstan. Ton RH is located in a village in the south of Kyrgyzstan and provides inpatient medical care for a population
Table 1. Characteristics of the Ton and Issyk-Kul Regional Hospitals of Kyrgyzstan.

\begin{tabular}{|l|c|c|}
\hline Characteristics & $\begin{array}{c}\text { Ton Regional Hospital } \\
\text { Village insouthern } \\
\text { Kyrgyzstan }\end{array}$ & Issyk-Kul Regional Hospital \\
\hline Hospital location & 53,245 & Resort in northern Kyrgyzstan \\
\hline Regionalpopulation & 90 & 96,450 \\
\hline Number of beds & 11 & 12 \\
\hline Number of wards & 116 & 141 \\
\hline Number of staff & 15 & 27 \\
\hline Physicians & 64 & 75 \\
\hline Nurses & 23 & 25 \\
\hline Nurse assistants & 14 & 13 \\
\hline Other workers & 3,146 & 4,067 \\
\hline Inpatient number (2013) & $0.7 \%$ & $1.4 \%$ \\
\hline Mortality rate & 300,000 USD & 490,000 USD \\
\hline Annual budget (USD) & & \\
\hline
\end{tabular}

of 53,350 people. There are 95 beds in five clinical wards (general, infectious, surgical, delivery, and recovery) and six additional units (admission room, lab and diagnostic, X-ray, transfusion, rehabilitation). It is staffed by 116 workers: 15 physicians (12.9\%), 64 nurses (55.2\%), 23 assistants of nurses (19.8\%), and 14 other workers (12.1\%). The hospital treated 3,146 patients in 2013. The average hospital stay was 7.8 days. The mortality rate was $0.7 \%$, primarily due to cardiovascular and respiratory diseases, trauma, and toxicity. The hospital's annual budget was 300,000 USD.

Issyk-Kul RH is located in the north of Kyrgyzstan and renders medical services to a population of 76,450 people in the region. It has 90 beds in five clinical wards (general, surgical, delivery, infectious and recovery) and seven additional units (admission room, lab, ultrasound diagnostic, X-ray, transfusion, rehabilitation, and sterilization). It is staffed by 141 workers: 27 physicians (19.4\%), 75 nurses (55.2\%), 25 nurse assistants (15.6\%), and 13 other workers (9.8\%). In 2013, 4,067 patients received treatment. The average hospital stay was 7.1 days. The hospital mortality rate was $1.4 \%$, primarily from cardiovascular diseases, trauma, alcohol intoxication, and respiratory diseases. Its annual budget of the hospital at the time of the study was 490,000 USD. Ton $\mathrm{RH}$ is located in village with poor well-being of the population and weak infrastructure. There are shortages of physicians and modern medical equipment. Issyk-Kul RH is situated in a resort city with a strong infrastructure and high standard of living. This hospital has a sufficient number of physicians and good medical equipment. The annual budget of Issyk-Kul RH was 190,000 USD greater than that of Ton $\mathrm{RH}$, due to the greater number of patients who received medical services.

Table 2 shows socio-demographic characteristics of the 500 participants who were involved in this medico-social study. Of these, 230 (46\%) were patients of Ton RH and 270 (54\%) were from Issyk-Kul RH. Female patients were dominant in both hospitals: 146 (63.5\%) in Ton RH and 187 (69.3\%) in the Issyk-Kul RH. The majority of respondents were from 40 to 49 years old: 75 (32.6\%) in the Ton $\mathrm{RH}$ and 88 (32.6\%) in the Issyk-Kul RH. Patients with secondary and specialized education were the majority: 112 (48.7\%) and 130 (48.1\%), respectively. Respondents were divided into four social groups (servant, worker or business owner, retired or disabled, and unemployed) with retired the majority at Ton $\mathrm{RH}(37.4 \%)$, and unemployed at Issyk$\mathrm{Kul} \mathrm{RH} \mathrm{(34.1 \% ).} \mathrm{Patients} \mathrm{who} \mathrm{were} \mathrm{married} \mathrm{tended} \mathrm{to} \mathrm{be} \mathrm{the} \mathrm{highest}$ proportion: $34.8 \%$ in the Ton RH and $45.2 \%$ in the Issyk-Kul RH. There was a significant difference in social status $(\mathrm{p}=0.003)$, and marital status ( $\mathrm{p}=0.005$ ) between the hospitals. 
Shayahmetov B (2016) The Study on Patient Dissatisfaction with Medical Services to define an Indicator of the Healthcare Management in the Ton and Issyk-Kul Regional Hospitals of Kyrgyzstan

Table 2. Socio-demographic characteristics of patients in Ton and Issyk-Kul Regional Hospitals of Kyrgyzstan.

\begin{tabular}{|l|c|c|c|c|}
\hline Characteristics & $\begin{array}{c}\text { TonRegional } \\
\text { Hospital n (\%) }\end{array}$ & $\begin{array}{c}\text { Issyk-Kul } \\
\text { Regional } \\
\text { Hospital n (\%) }\end{array}$ & Totaln (\%) & p-value \\
\hline Total & $230(100)$ & $270(100)$ & $500(100)$ & 0.194 \\
\hline Age groups & $15(6.5 \%)$ & $19(7.0 \%)$ & $34(6.8 \%)$ & \\
\hline $18-29$ & $57(24.8 \%)$ & $62(23.0 \%)$ & $119(23.8 \%)$ & \\
\hline $30-39$ & $75(32.6 \%)$ & $88(32.6 \%)$ & $163(32.6 \%)$ & \\
\hline $40-49$ & $44(19.1 \%)$ & $71(26.3 \%)$ & $115(23.0 \%)$ & \\
\hline $50-59$ & $39(17.0 \%)$ & $30(11.1 \%)$ & $69(13.8 \%)$ & \\
\hline$>60$ & $84(36.5 \%)$ & $83(30.7 \%)$ & $167(33.4 \%)$ & \\
\hline Gender & $146(63.5 \%)$ & $187(69.3 \%)$ & $333(66.6 \%)$ & \\
\hline Male & & & & 0.859 \\
\hline Female & $33(14.3 \%)$ & $35(13.0 \%)$ & $68(13.6 \%)$ & \\
\hline Education & $112(48.7 \%)$ & $130(48.1 \%)$ & $242(48.4 \%)$ & \\
\hline High school/University & $85(37.0 \%)$ & $105(38.9 \%)$ & $190(38.0 \%)$ & \\
\hline Special school/College & & & & 0.003 \\
\hline Secondary school & $21(9.2 \%)$ & $37(13.7 \%)$ & $58(11.6 \%)$ & \\
\hline Social status & $73(31.7 \%)$ & $68(25.2 \%)$ & $141(28.2 \%)$ & \\
\hline Servant & $86(37.4 \%)$ & $73(27.0 \%)$ & $159(31.8 \%)$ & \\
\hline Worker,business owner & $50(21.7 \%)$ & $92(34.1 \%)$ & $142(28.4 \%)$ & \\
\hline Retiree,disabled & $80(34.8 \%)$ & $122(45.2 \%)$ & $202(40.4 \%)$ & \\
\hline Unemployed & $22(9.5 \%)$ & $39(14.4 \%)$ & $61(12.2 \%)$ & \\
\hline Marital Status & $71(30.9 \%)$ & $67(24.8 \%)$ & $138(27.6 \%)$ & \\
\hline Married & & & & \\
\hline Unmarried & & & & \\
\hline Divorced & & & & \\
\hline Widowed & & & & \\
\hline & & & & \\
\hline
\end{tabular}

a: Chi-squared test

Table 3 presents hospital organizational aspect items. This aspect includes 11 criteria. Long waiting periods for hospitalization and untimely physician rounds caused the greatest dissatisfaction at Ton $\mathrm{RH}$ (79.1\% in both characteristics). At Issyk-Kul RH, most of the patients (78.5\%) were dissatisfied with securing of nutrition and food quality, followed by provision of linen (75.2\%). There was a statistically significant difference in the criterion of timely observation by doctors between the two RHs.

Table 4 concerns nine parameters of competency. Significant differences were obtained at both hospitals in dissatisfaction with friendliness and attentiveness of nurses toward patients $(\mathrm{p}<0.001)$, quality and completeness of primary medical check $(\mathrm{p}=0.004)$, and friendliness and attentiveness of doctors $(p=0.046)$. Regarding the information aspect, $68.7 \%$ of patients at Ton RH and $69.3 \%$ at Issyk$\mathrm{Kul} \mathrm{RH}$ were dissatisfied with the availability of informational material. The total number of dissatisfied patients of both RHs were 235: 111 (47.2\%) from Ton RH and 124 (52.8\%) from Issyk-Kul RH.

\section{Discussion}

In terms of organizational aspects, timely observation by doctors seems to be one of the areas of critical dissatisfaction at Ton $\mathrm{RH}$ compared to Issyk-Kul RH. Quality and completeness of primary medical check and friendliness and attentiveness of doctors, concerning of aspects of competence was more common at Issyk-Kul RH than at the Ton RH. We think these differences between the RHs are due to the insufficient number of physicians in rural area; one doctor has to play multiple roles such as surgeon and doctor of the admission room. This causes serious negative effects on the quality of medical services and attentiveness to patients. Many studies about outpatient services have shown related problems [7-13].
In our study, the result of dissatisfaction with organizational aspects such as waiting period for hospitalization and timely observation by doctors $(79.1 \%$ in both criteria in Ton $\mathrm{RH}, 73.0 \%$ and $68.1 \%$ correspondingly in Issyk-Kul RH) were the almost similar with the study conducted in Arkhangelsk, Russia (79.0\% and 71.6\%) [14]. It might be connected with poor management of hospitals and insufficient medical staff, work overload, and improper conducting of duties.

Level of patient dissatisfaction with trust of doctor's competence were significantly higher (49.3\% in Ton RH and 60.9\% in Issyk-Kul RH) in our study in comparison with a study in Volgograd, Russia (24.0\%) $[15,16]$. These results might be caused by insufficient refresher training

Table 3. Patient dissatisfaction with organizational aspects in Ton and Issyk-Kul Regional Hospitals ofKyrgyzstan.

\begin{tabular}{|l|c|c|c|}
\hline \multirow{2}{*}{ Characteristics } & $\begin{array}{c}\text { TonRegional } \\
\text { Hospital } \\
\text { (n=230) }\end{array}$ & $\begin{array}{c}\text { Issyk-Kul } \\
\text { Regional } \\
\text { Hospital(n=270) }\end{array}$ & p-value \\
\cline { 2 - 4 } Dissatisfied & Dissatisfied & \\
\cline { 2 - 4 } & $\mathbf{n}(\%)$ & $\mathbf{n}(\%)$ & \\
\hline Waiting period for hospitalization & $182(79.1 \%)$ & $197(73.0 \%)$ & 0.109 \\
\hline Organization of reception & $170(73.9 \%)$ & $183(67.8 \%)$ & 0.133 \\
\hline Timely observation by doctors & $182(79.1 \%)$ & $184(68.1 \%)$ & 0.006 \\
\hline Securingdressing materials, syringes & $172(74.8 \%)$ & $200(74.1 \%)$ & 0.856 \\
\hline Securingnutrition, food quality & $175(76.1 \%)$ & $212(78.5 \%)$ & 0.517 \\
\hline Lab and medical equipment, test & $163(70.9 \%)$ & $197(73.0 \%)$ & 0.603 \\
\hline completeness & $156(67.8 \%)$ & $203(75.2 \%)$ & 0.068 \\
\hline Provision of linen & $160(69.6 \%)$ & $166(61.5 \%)$ & 0.059 \\
\hline Drug security & $148(64.3 \%)$ & $191(70.7 \%)$ & 0.127 \\
\hline Hospital sanitation, regular unit cleaning & $169(73.5 \%)$ & $196(72.6 \%)$ & 0.824 \\
\hline $\begin{array}{l}\text { Availability of shower,hot water, } \\
\text { conditioner }\end{array}$ & & & \\
\hline Accessibility of specialty consultants & $165(71.7 \%)$ & $189(70.0 \%)$ & 0.670 \\
\hline
\end{tabular}

\section{a: Chi-square test}

b: 1-completely dissatisfied, 2-somewhat dissatisfied, 3-neutral (average), 4-somewhat satisfied, 5-completely satisfied. Therefore, we categorized 1-3 points as"dissatisfied" for each characteristic.

Table 4. Patient dissatisfaction with aspect of competency in Ton and Issyk-Kul Regional Hospitals of Kyrgyzstan.

\begin{tabular}{|l|c|c|c|}
\hline \multirow{2}{*}{ Characteristics } & $\begin{array}{c}\text { Ton Regional } \\
\text { Hospital } \\
\text { (n=230) }\end{array}$ & $\begin{array}{c}\text { Issyk-Kul } \\
\text { Regional Hospital } \\
\text { (n=270) }\end{array}$ & p-value \\
\cline { 2 - 4 } & Dissatisfied & Dissatisfied & \\
\cline { 2 - 4 } & $\mathbf{n}(\mathbf{\%})$ & $\mathbf{n}(\%)$ & \\
\hline $\begin{array}{l}\text { Quality and completeness of primary } \\
\text { medical check }\end{array}$ & $160(69.6 \%)$ & $218(80.7 \%)$ & 0.004 \\
\hline Trust in competence of doctor & $133(49.3 \%)$ & $164(60.7 \%)$ & 0.508 \\
\hline Trust in competence of nurses & $153(66.5 \%)$ & $180(66.7 \%)$ & 0.973 \\
\hline Friendliness and attentivenessof doctors & $147(63.9 \%)$ & $195(72.2 \%)$ & 0.046 \\
\hline Friendliness and attentiveness of nurses & $123(53.5 \%)$ & $193(71.5 \%)$ & $<0.001$ \\
\hline Accessibility of doctor explanation & $129(56.1 \%)$ & $147(54.4 \%)$ & 0.713 \\
\hline Securing of rights and confidentiality & $132(57.4 \%)$ & $155(57.4 \%)$ & 0.997 \\
\hline Courtesy of medical staff to family & $113(49.1 \%)$ & $128(47.4 \%)$ & 0.701 \\
\hline $\begin{array}{l}\text { Patient's participation in treatment } \\
\text { decision-making }\end{array}$ & $164(71.3 \%)$ & $196(72.6 \%)$ & 0.749 \\
\hline
\end{tabular}

a: Chi-square test

b: 1-completely dissatisfied, 2-somewhat dissatisfied, 3-neutral (average), 4-somewhat satisfied, 5-completely satisfied. Therefore we categorized 1-3 points as"dissatisfied" for each characteristic. 
Shayahmetov B (2016) The Study on Patient Dissatisfaction with Medical Services to define an Indicator of the Healthcare Management in the Ton and Issyk-Kul Regional Hospitals of Kyrgyzstan

for staff. The results of the previous study in Volgograd concerning patient dissatisfaction with nutrition provision $(78.4 \%)$ were the almost similar to those of our study $(76.1 \%$ in Ton $\mathrm{RH}$ and 78.5 in Issyk-Kul RH) [16]. This may be due to irrational use and distribution of financial resources.

In studies conducted in Japan (26.5\%) and USA (34.6\%), patients were found to be less dissatisfied with the nurse friendliness than our study (53.3\% in Ton RH and 71.5\% in Issyk-Kul RH) [17,18]. The study also indicates the necessity of communication training for nurses.

Patient satisfaction is essential to obtaining a comprehensive understanding of patients' needs and their opinions of the services received [19]. This study also indicated areas for improvement from the respondents' perspectives. Patient dissatisfaction can lead to poor treatment compliance and result in poor health outcomes [20]. As a recommendation, an increase in community participation activities by clinical staff should be implemented to learn patients' expectations and opinions about hospital services.

One limitation of this study was that it was conducted in only two RHs of Kyrgyzstan. This is the first study focusing on patient dissatisfaction with medical services of hospital in Kyrgyzstan and authors had no possibility to compare the results to previous studies.

Patients often have high expectations of the services from clinical staff. Therefore, proper training of codes of conduct and courtesy should be provided to both clinical and office staff. Incentives and negative consequences should be completed based on regular performance reviews. It is also strongly suggested that necessary and adequate amounts of medications, dressing materials should be available in the hospitals [20].

In conclusion, patients receiving hospital services are responsible for conveying a hospital's good image. Securing high patient satisfaction is equally important for a hospital management team.

\section{Acknowledgements}

We would like to honestly express our gratefulness to Dr. Bokchubaev Ernis, from Kyrgyz State Medical Institute of Advanced Qualification, for his significant guidance and recommendations. We thank the administrations and relevant staff of Ton and Issyk-Kul RHs who ably assisted in survey completion and data collection. In addition, we are gratefully indebted to all survey participants, whose responses helped us conduct this study.

\section{Conflicts of interest}

The authors declare no conflicts of interest.

\section{References}

1. Ibraimova A, Akkazieva B, Ibraimov A, Manzhieva E, Rechel B (2011) Kyrgyzstan: Health system review. Health Syst Transit 13: xiii, xv-xx, 1-152. [Crossref]

2. Andersen RM, McCutcheon A, Aday LA, Chiu GY, Bell R (1983) Exploring dimensions of access to medical care. Health Serv Res 18: 49-74. [Crossref]

3. Hall JA, Dornan MC (1990) Patient sociodemographic characteristics as predictors of satisfaction with medical care: a meta-analysis. Soc Sci Med 30: 811-818. [Crossref]

4. Swan JE, Sawyer JC, Van Matre JG, McGee GW (1985) Deepening the understanding of hospital patient satisfaction: fulfillment and equity effects. $J$ Health Care Mark 5 7-18. [Crossref]

5. Donabedian A (1976) Measuring and evaluating hospital and medical care. Bull N Y Acad Med 52: 51-59. [Crossref]

6. Anderson RT, Camacho FT, Balkrishnan R (2007) Willing to wait?: the influence of patient wait time on satisfaction with primary care. BMC Health Serv Res 7: 31. [Crossref]

7. Chanawongse K (1994) Understanding primary health care management: from theory to practical reality. Nakhon Phathom: ASEAN Institute for Health Development, Mahidol University, Bangkok.

8. Kunders GD (1998) Hospital planning, design and management. Tata McGraw-Hill Publishing Company Ltd., New Delhi, India, Pp: 328-342

9. Wong EL, Coulter A, Hewitson P, Cheung AW, Yam CH, et al. (2015) Patient experience and satisfaction with inpatient service: development of short form survey instrument measuring the core aspect of inpatient experience. PLoS One 10: e0122299. [Crossref]

10. Drugus D, Azoicai D (2015) Degree of patient satisfaction with health care performance assessed by marketing surveys. Rev Med Chir Soc Med Nat Iasi 119: 221-225.

11. Bankauskaite V, Saarelma O (2003) Why are people dissatisfied with medical care services in Lithuania? A qualitative study using responses to open-ended questions. Int J Qual Health Care 15: 23-29. [Crossref]

12. Kairys J, Zebiene E, Sapoka V, Zokas I (2008) Satisfaction with organizational aspect of health care provision among Lithuanian physicians. Cent Eur J Public Health 16 29-33. [Crossref]

13. Siburina TA, Barsova GN, Laktionova LV (2013) Methodological approaches to survey patients' satisfaction with high-tech medical care. (in Russian) E-sci J Soc Health.

14. Svetlichnaya TG, Tsyganova OA (2011) Medical-sociological approach to analysis of population satisfaction with quality of medical services. (in Russian) E-sci J Soc Health.

15. Petrov SV (2009) Patient's satisfaction with medical health as indicator of quality system of management. (in Russian) J Rus Med Acad 4: 56-57.

16. Schkarin VV (2012) The analysis of patient satisfaction in the hospital of the Volgograd region. ( in Russian) J Med Tech.

17. Tokunaga J, Imanaka Y, Nobutomo K (2000) Effects of patient demands on satisfaction with Japanese hospital care. Int J Qual Health Care 12: 395-401. [Crossref]

18. Boudreaux ED, Mandry CV, Wood K (2003) Patient satisfaction data as a quality indicator: a tale of two emergency departments. Acad Emerg Med 10: 261-268. [Crossref]

19. Shaikh BT, Rabbani F (2005) Health management information system: a tool to gauge patient satisfaction and quality of care. East Mediterr Health J 11: 192-198. [Crossref]

20. Cleary PD, McNeil BJ (1988) Patient satisfaction as an indicator of quality care. Inquiry 25: 25-36. [Crossref]

Copyright: (C2016 Shayahmetov B. This is an open-access article distributed under the terms of the Creative Commons Attribution License, which permits unrestricted use, distribution, and reproduction in any medium, provided the original author and source are credited. 